\title{
TMI or OMG: Jeff Rice Laughs At The King With No Clothes
}

\author{
Craig Saper \\ University of Maryland Baltimore County
}

Rice, Jeffrey. Authentic Writing. University of Pittsburgh Press, 2021.

The reviews in this issue will appear just at the time we are told by administrators and managers that we will soon return to normal, but with greater virtue and authenticity, and with more openness to others' points of view. The books reviewed in this issue will likely provoke readers. They are meant to spur outrage about those supposed values of the new and improved academic discourse as we return to in-person work. Because Authentic Writing is a provocation, perhaps this review should be on a sticker on the book's cover like a movie rating, for Mature Audiences, or like a health warning on a pack of cigarettes, or as a complimentary face mask to be worn while reading!

Jeff Rice's latest challenge to the academic norms of our day, make it a challenge to write a review about the book's academic legitimacy and scholarly authenticity. Although a seemingly obvious point, perhaps even banal, in this case the book is about the rhetorical tropes and formats of scholarly authenticity in writing, and the book review is perhaps the foundation of this scaffolding of scholarly authenticity.

Rice discovers authentic writing in its seeming opposite, the stereotypical details of his personal life. The details used to demonstrate his methodology of authentic writing are chosen specifically as not symptomatic of larger ideological tensions or contradictions. Instead of auto-ethnography or memoir, Rice makes clear that he does not use his own rather pedestrian life as symptomatic of larger trends, as in auto-ethnography. He does not use the arc of his biographical achievements as memoir. He does not use anecdotes about food, drink, children, travel, and exercise to demonstrate the "complexity of hermeneutics" nor the "expressivism" of "personal writing." Rather he mixes mundane anecdotes and details (from personal stories and popular culture) with profound insights about disciplinary knowledge.

There are two overlapping arguments: 1) cultural theory and rhetorical analysis is usually "constantly engaging with clues for some vaster reality, as if we are always on the verge of pulling back the Wizard of Oz's curtain and revealing what we thought was $X$ instead is really $Y$;" and 2) although not about social media, the book "assumes social media influence on contemporary expression and writing as it navigates questions of authenticity and what it means to perform scholarly writing in an age dominated by personal, shared and social expression." 
Rice's project examines cultural scenes much like Roland Barthes in Mythologies except for the crucial difference that Rice does not elevate these scenes and situations to the level of a code or ideology. Instead, Rice looks for what remains, after our scholarly inclination to read everything as a representation of a higher meaning. In that sense, it is almost as if Rice reads what seem like moments in Mythologies, but with a lens that includes Barthes' much later methods in Camera Lucida -- a study in which the punctum functions as the strategy of reading of details that fall outside of the studium (everything we teach and learn in school). The punctum does not rise to cultural significance nor is it read in a way that explores other non-ideological avenues of personal and authentic meaning. Rice discusses Greg Ulmer's "popcycle" and Barthes' "punctum" as foundational concepts in developing the theory of "authentic writing."

Although neither topic nor thesis, the style of Rice's manuscript is key to fully appreciating the theoretical argument: authentic writing, here involves writing scholarship humorously. Using the method of "authentic writing" often leads Rice to offer profound insights about both academic writing and work and everyday life, wrapped up in what might strike some readers as an elaborate joke. Authentic writing involves -- maybe risks -- Rice's own ethos as an academic as it uncovers the mundane details of his everyday life that support his work as an authentic scholar, writer, professor, and department chair or administrator. Although Rice reads stories and details without interpreting them as symptomatic of larger cultural contradictions, I am still tempted to read these same stories and details in terms of larger problems.

Rice is an important scholar in "rhetoric and composition" working today, and this book's rigorous research on different claims to authentic academic writing might reinforce that reputation or put a target on his back; from this book, filled with his personal life, one might dislike the author and his personal life even as one is moved by the bravery of the argument against the current forms of often cloying auto-ethnographic cultural criticism. That is, disliking Rice is precisely the argument for adopting this book. Rice uses himself as the provocation to see the entire enterprise of the authentic writing as problematic.

Precisely because of his outré argument and style with discussions of "urination," or "sweating" during yoga, to name just two of the many banal and bodily matters discussed, the book will be contentious. It challenges the dominant methods of Rice's academic disciplines, including close readings in both ideological critiques and, more recently, auto-ethnography. Perhaps fittingly, Rice's book positions its narrator as an outsider in the profession, even as his scholarship in this book makes an important claim to rethink what is centrally involved in legitimate scholarship. Maybe in another context it would be unfair to include details of an author's personal life in a scholarly evaluation of a book, but in this case the author builds a case -- a rigorously researched case -- on the explicitly trivial moments in his life.

Rice openly admits that some might fault him for including somewhat embarrassing situations and mundane photographic images of his two children as inappropriate. He shows them bored, eating distractedly, or watching passively in front a flight of beer; he includes one child's scatological scribbles about the "university of butt" and the words "poooo poooo!" scrawled around a primitive drawing of a figure -- well, l'm not sure what the figure is doing -- teaching or defecating? It is not anything like the voyeurism of Sally Mann's photographs of her -explicitly collaborating -- children, but it did remind me of a prosaic version of those works. Again, that is Rice's argument that we work as scholars within and through our personal lives including the joys and frustrations of parenting. Rice recognizes the issues involved in sharing the child's drawing: 
His drawing becomes an extension of the personal. Facebook is an extension of my expression. We can doubt that expression's authenticity (is he joking? is he serious? does he think it is acceptable to share his children's art on social media?

The use of Rice's children becomes part of a nuanced argument that depends on a two-step process; first, one is struck by the privilege of the Rice children -- eating in China, Denmark, Israel, etc. -- that should be profound, lifechanging experiences; second, one sees that the children are often bored, involved in tedious activities, or not having the hoped-for sea-change experience that traveling abroad promises. So, the inconsequential appears everywhere, imbricated even in situations that we think of as greatly significant -- like our professional lives, academic writing, or the experiences we hope to choreograph for students and children.

Rice connects these scenes through an engagement with popular media, for example describing an episode from Louis, in which comedian Louis C. K., in the midst of grocery shopping with his young daughters, realizes that he must go to the bathroom and eventually, and hilariously, "shits his pants," as an example of the comedy involved in everyday parental failures encountered while trying to write and function in the professional world. The way Rice recounts the episode of the television program, and connects it to his argument, makes the insights puncture our professional defenses with humor. Still, it also inevitably will remind the readers about the larger ideological issues involved in the claims of sexual harassment and discussions of public masturbation by Louis C.K. Similarly, other bodily and cringe-inducing topics appear throughout the book. Our professional pedagogy and scholarship usually excludes the banal and other shit.

I found myself laughing (sometimes sympathetically, often uncomfortably) through much of the book in recognition of trivial situations in my own life as a writer, academic, and respected professional. How often do you read profound insights about heady theoretical claims about rhetoric, writing and the craft of composition that make you laugh aloud? Of course, there is a risk here. The book also intends to make the reader slightly uncomfortable by willfully excluding larger ideological implications. That strategy challenges everything "we" have learned in school: that everything is signifying a larger ideological system. This book-manuscript makes fun (successfully) of that reified frame of reference even as it meticulously makes us aware of the rhetorical and theoretical claims about the personal from other scholars: to be asleep to the machinations of how our living in culture "positions" us and reinforces "identity" and "subject formation." The resulting frisson may fall flat. For this reader it worked, and made me want to teach this eventual book to my introductory classes.

One chapter, on the author's practice of hot Bikram Yoga in which students and practitioners do various poses in a room over 100 degrees Fahrenheit, seemed out of place with the other chapters. The other chapters spoke to the place of the boring and banal in our scholarship. This chapter seemed to have a different tone. Besides the reference to Norman Mailer's story about Yoga, the chapter was not intended to be funny. Earlier Rice cites Gregory L. Ulmer's theory of the "popcycle," an intended pun combining popsicle and popular culture cycles, illuminating how popular culture and personal stories circulate always (usually unacknowledged) in our professional lives and as crucial parts of knowledge production. In this chapter, I just kept thinking of the larger ideological issues involving claims of harassment by Bikram Choudhury, especially since the release of the documentary about, according to the press release, the "dark origin story of Bikram Yoga" ... and its spectacular "success and its downfall ... filing for bankruptcy in 2017." Despite the cringe-inducing reaction that the name "Bikram Yoga" induces, this reference is not a weakness to me, however if Rice included a footnote acknowledging the controversy it could strengthen his argument that his own trite experiences don't always have to rise to the level of ideological contradictions. Footnotes could also acknowledge the controversy in the Louis 
CK example, or the male privilege inherent in urinating on the side of the road, while nevertheless arguing reading these situations and anecdotes as not necessarily rising to consequential implications. My complaint about this chapter on yoga is not that Rice should acknowledge Bikram's fall from grace, but rather stylistically I want to yell out to the author, "more banality, more fun, more embarrassing situations in this chapter -- sweating in the Yoga studio just doesn't work for me."

Maybe that is both the point and problem with academic writing that demands identification with the authentic voice of the critic; what if the critic is a misanthrope? And, what if those "virtue hoarders," to borrow Catherine Liu's brilliant phrase, use virtuous authenticity as a cudgel to maintain the economic privilege of the professional managerial class! Virtue Hoarders, reviewed elsewhere in this issue, could be a companion piece to this book on authentic writing. Imagine this character, Jeff Rice, standing naked, sweating, and gross in front of us to provoke a collective enervation and recognition that academics involved in authentic writing are all a sweaty mess masquerading as virtuous ideals.

\section{Cite this Essay}

Saper, Craig. "TMI or OMG: Jeff Rice Laughs At The King With No Clothes." Rhizomes: Cultural Studies in Emerging Knowledge, no. 37, 2021, doi:10.20415/rhiz/037.r03

RHIZOMES ISSN 1555-9998 ^ 230 East Hall Bowling Green State University Bowling Green, OH 43403

Editors: Ellen Berry and Carol Siegel. Reviews editor: Craig J. Saper. Technical editor: Helen J Burgess 